\title{
THE MECHANISM OF THE RING-OPENING POLYMERIZATION OF LACTIDE AND GLYCOLIDE
}

\author{
F. E. KoHN*, J. G. van OMmen and J. FeIJEN \\ Department of Chemical Technology, Twente University of Technology, P.O. Box 217. 7500 AE \\ Enschede, The Netherlands
}

(Received 9 March 1983)

\begin{abstract}
To obtain more insight in the ring-opening polymerization of lactones, complex formation of the initiators tetraphenyltin, stannous octoate, tin tetrachloride, aluminjum bromide and triisobutylaluminium (TIBA), and the monomers $\mathrm{L}(-)$-lactide, D,L-lactide and glycolide was studied by i.r.-spectroscopy. When equimolar benzene or toluene solutions of initiators and monomers were combined, only complexes of aluminium bromide and D,L-lactide or glycolide, and of TIBA and $D, L-l a c t i d e$ or glycolide were observed. The complex formation was studied in detail by varying the initiator and monomer concentrations. From these results and theoretical considerations, it is concluded that complexes are formed by the coordination of a carbonyl oxygen of monomer and the aluminium atom of initiator. The corresponding polymers were formed when TIBA was used as an initiator. When $\mathrm{AlBr}_{3}$ was used, polymers were obtained only when traces of water were added. It is concluded that in the case of $\mathrm{AlBr}_{3}$ the actual initiating species is $\mathrm{HBr}$ and that the polymerization initiated with TIBA proceeds very probably through a coordinated insertion of the lactone monomer into the aluminium-carbon bond.
\end{abstract}

\section{INTRODUCTION}

Over the past 15 years there has been considerable interest in the application of poly(glycolic acid) PGA. poly(L- and D,L-lactic acid) PLLA and PDLA and of co-polymers of glycolic and L-lactic acid GA/LLA as biodegradable polymers in medicine and surgery [1]. Absorbable sutures prepared from PGA [2] and from GA/LLA co-polymers (molar ratio 90:10) [3] are commercially available. In our laboratories we have recently applied PDLA as temporary eardrum grafts in rats [4] and dogs.

Nowadays the preferred method for the preparation of high molecular weight PGA, PLLA and PDLA or corresponding co-polymers is the ringopening polymerization of the six-membered cyclic diesters glycolide (m.p. $87^{\circ}$ ), L-lactide (m.p. 95 ) and D,L-lactide (m.p. $127^{\circ}$ ), respectively, initiated with a suitable initiator, e.g. tin tetrachloride [5], stannous octoate or tetraphenyltin [6]. The ring-opening polymerization is schematically depicted in Scheme 1. The polymerization is preferably performed in the melt at higher temperatures, although lactide has also been polymerized successfully in solution under mild conditions [7].

Purified D,L-lactide, derived from the racemic mixture of $\mathrm{L}(+)$-lactic acid and $\mathrm{D}(-)$-lactic acid, is the

*Present address: Firet bv, P.O. Box 45, 3900 AA Veenendaal, The Netherlands.

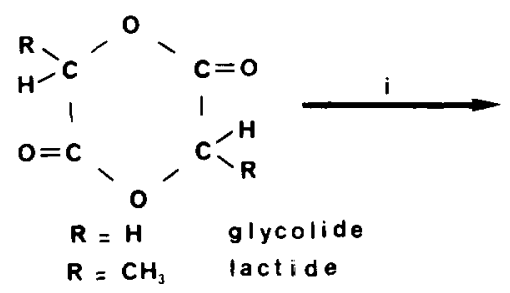

molecular 1:1 compound of both enantiomers $\mathrm{L}(-)$-lactide and $\mathrm{D}(+)$-lactide [8]. Lactide and glycolide can be considered as modified lactones and their polymerization behaviour has been reported to be rather similar to that of $\delta$-valerolactone [9].

In several publications, mechanisms have been proposed for the initiation or, in a broader sense, for the polymerization of lactones. These mechanisms can be subdivided into (i) cationic $[5,10-15)$; (ii) anionic [16-20]; and (iii) coordination-insertion types [21-27]. The latter type is considered by Young et al. [28] as the intermediate case between the two other modes of initiation. In spite of the many data published on the polymerization of lactones, especially of $\beta$-propiolactone and $\epsilon$-caprolactone [29-31], the question whether a lactone ring is opened by acyl-oxygen bond cleavage or by alkyl-oxygen bond cleavage is still disputed. Another as yet insufficiently answered question is related to the true nature of the initiating species.

With the exception of the results obtanned by Kogan et al. [15], there are virtually no data on the interaction between the initiator and the lactone monomer prior to the actual ring opening. Investigation of this interaction is the subject of this study. For that purpose the interaction between initiators and glycolide, L-lactide and D,L-lactide, respectively, was studied by i.r.-spectroscopy. In the study by Kogan et al., only precipitates which could

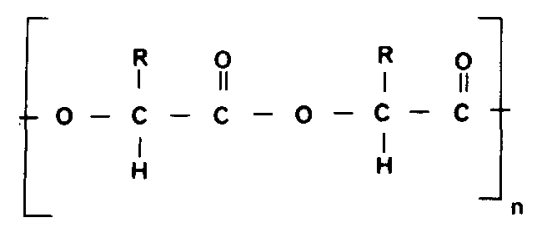

Scheme 1. Ring-opening polymerization of glycolide and lactide. 
be isolated after mixing equimolar benzene solutions of a Lewis acid and glycolide were studied by i.r.-spectroscopy. In this way solid compounds of glycolide and the strong Lewis acids $\mathrm{TiCl}_{4}$ (molar ratio $1: 1), \mathrm{ZrCl}_{2}(1: 2)$ and $\mathrm{AlBr}_{3}(1: 4)$ were obtained and compared with pure glycolide.

In the present study, mainly complex formation in solution (cf. ref [32]) and some isolated precipitates were studied by i.r.-spectroscopy. Occasionally complex formation in the melt was investigated.

\section{EXPERIMENTAL}

\section{Materials}

Initiators or potential initiators. Tin tetrachloride, tetraphenyltin (purchased from Polysciences) stannous octoate (tin- (II)- salt of 2-ethylhexoic acid; purchased from Polysciences) and triisobutylaluminium (TIBA; purchased from Schuchard, purity 93-95\%) were used without further purification. Aluminium bromide was sublimed $\left(p=0.1 \mathrm{~mm} ; T=95^{\circ}\right)$ and stored under $\mathrm{N}_{2}$.

Monomers. L ( - )-lactide (purchased from Polysciences) was recrystallized twice from ethyl acetate, dried in a vacuum oven at room temperature and stored in a desiccator over $\mathrm{P}_{2} \mathrm{O}_{5}$ (m.p. $95^{\circ}$ ). The preparation of D,L-lactide (m.p. $127^{\circ}$ ) from the racemic mixture of $\mathrm{L}(+)$-lactic acid and $\mathrm{D}(-)$-lactic acid was based on the procedures developed by Kulkarni et al. [33] and by Sinclair and Gynn [34]. Crude D,L-lactide was recrystallized several times from ethyl acetate in order to separate the compound melting at $127^{\circ}$ from the meso-lactide melting at $43^{\circ}$ [8]. Purified D,L-lactide (m.p. $127^{\circ}$ ) was dried in a vacuum oven at room temperature and stored in a desiccator over $\mathrm{P}_{2} \mathrm{O}_{5}$. Glycolide (m.p. $87^{\circ}$ ) was prepared according to Lowe [35] and to Sorenson and Campbell [36]. It was recrystallized several times from ethyl acetate, dried in an oven at room temperature and stored in a desiccator over $\mathrm{P}_{2} \mathrm{O}_{5}$. During the preparation of glycolide, a considerable amount of powdered, low molecular weight poly(glycolic acid) mixed with antimony trioxide has to be introduced in small portions into the reaction vessel which is heated at $270-285^{\circ}$ and maintained at a pressure $<15 \mathrm{~mm}$. In the original procedure [35], a supply vessel connected by means of heavy-walled, flexible tubing to a stopcock fitted into the inlet neck of the three-necked reaction flask is recommended. In our experience the use of this equipment led very soon to accumulation of solidified glycolide distillate and consequent plugging of the stopcock and tubing. Therefore the simple dosage system shown in Fig. 1a was developed. By slowly turning the individual supply vessels one after another, the contents can be administered in a controlled way.

\section{Methods}

Complex formation in solution. Toluene or benzene (Merck, pro analysis) was dried on molecular sieves (Union Carbide, 13X) and degassed and saturated with purified $\mathrm{N}_{2}$ [32]. The $\mathrm{O}_{2}$ and $\mathrm{H}_{2} \mathrm{O}$ contents of the purified $\mathrm{N}_{2}$ which was used throughout all experiments were $<1 \mathrm{ppm}$.

A typical procedure for the preparation and i.r.-spectroscopic investigation of a complex of $D, L$-lactide and $\mathrm{AlBr}_{3}$ was as follows. Glassware, syringes and needles were dried overnight at $120^{\circ}$. A polymerization tube [37] was

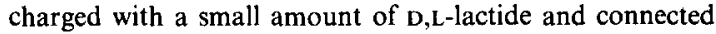
by means of a special adaptor (Fig. 1b) and vacuum tubing to a vacuum system designed for experiments under $\mathrm{N}_{2}$ [38]. In order to remove traces of water and other contaminating solvents, the polymerization tube was placed in an oil bath (maximum temperature $100-120^{\circ}$ ) and the D,L-lactide was sublimed slowly onto the upper part of the tube at reduced pressure $(0.1 \mathrm{~mm})$. The amount of $D, L$-lactide lost during the sublimation process is negligible. Next the tube was purged

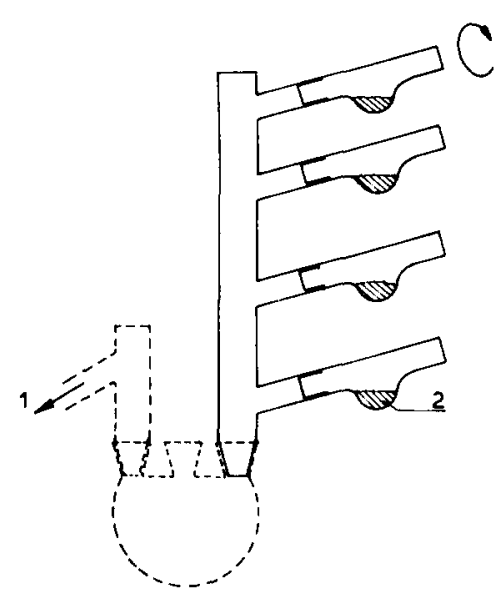

(a)

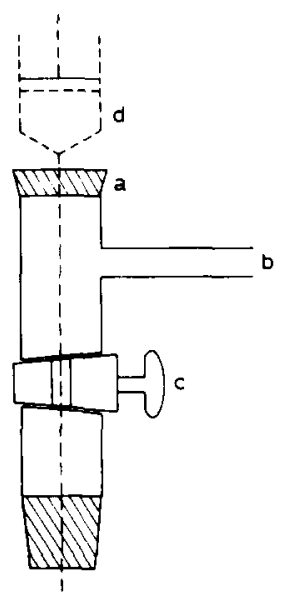

(b)

Fig. 1. (a) Dosage system for the administration of powdered material to an evacuated reaction vessel. (b) Adaptor.

with $\mathrm{N}_{2}$ and toluene was introduced through the septum. After D,L-lactide had dissolved, the solution was transferred through a septum into a reaction vessel using a syringe previously purged with $\mathrm{N}_{2}$. This reaction vessel was previously connected to the vacuum system when still hot, and was purged with $\mathrm{N}_{2}$. A solution of sublimed $\mathrm{AlBr}_{3}$ in toluene was prepared in a dry box and injected through the septum to the reaction vessel which contained the D, L-lactide solution. After $5 \mathrm{~min}$ a sample of the combined solution was transferred through the septum of the reaction vessel into a syringe previously purged with $\mathrm{N}_{2}$. The solution was then quickly injected into an i.r.-solution cell which was also purged with $\mathrm{N}_{2}$. The i.r.-spectrum was recorded on a Perkin-Elmer 357 grating i.r.-spectrophotometer. Toluene was placed in a reference cell to compensate for toluene absorption. When TIBA was used instead of $\mathrm{AlBr}_{3}$, it was added pure or as a solution in toluene. When complex formation of $\mathbf{L}(-)$-lactide and tetraphenyltin, stannous octoate or $\mathrm{SnCl}_{4}$ was investigated, $\mathrm{L}(-)$-lactide was treated in the same way as D,L-lactide (maximum sublimation temperature $100^{\circ}$ ) $\mathrm{SnCl}_{4}$ was added pure or as a solution in toluene. Stannous octoate was added as a solution in toluene. Tetraphenyltin was added as a solution in benzene; in the latter $L(-)$-lactide was also dissolved in benzene. For experiments under $\mathrm{N}_{2}$ at elevated temperatures including solution polymerizations, the reaction vessel (see above) was equipped with a condenser which was connected at the top to the vacuum system. When glycolide was used, this monomer was also sublimed (maximum temperature $95^{\circ}$; 
Table 1. Observed complex formation of lactide or glycolide and several (potential) initiators in solutions

\begin{tabular}{|c|c|c|c|c|c|}
\hline Monomer & Initiator & Solvent & $\begin{array}{c}C^{*} \\
\left(\mathrm{moll}{ }^{1}\right)\end{array}$ & $\begin{array}{c}T \\
(C)\end{array}$ & $\begin{array}{l}\text { Complext } \\
\text { formation }\end{array}$ \\
\hline$L(-)$-Lactide & Tetraphenyltin & Benzene & 0.01 & 20 & - \\
\hline L $(-)$-Lactide & Tetraphenyltin & Benzene & 0.05 & 80 & - \\
\hline $\mathrm{L}(-)$-Lactide & Stannous octoate & Toluene & 0.1 & 20 & - \\
\hline L( - )-Lactide & Stannous octoate & Toluene & 0.1 & 111 & - \\
\hline$L(-)$-Lactide & $\mathrm{SnCl}_{4}$ & Toluene & 0.1 & 111 & - \\
\hline 1),L-Lactide & $\mathrm{SnCl}_{4}$ & Toluene & 0.1 & 20 & - \\
\hline 1),L-Lactide & $\mathrm{AlBr}_{3}$ & Toluene & 0.1 & 20 & + , Soluble \\
\hline D. L-Lactide & TIBA & Toluene & 0.1 & 20 & + , Soluble \\
\hline Glycolide & $\mathrm{AlBr}_{3}$ & Toluene & 0.1 & $80-100$ & + , Soluble + \\
\hline Glycolide & TIBA & Toluene & 0.1 & 20 & + , Soluble \\
\hline
\end{tabular}

*Equal amounts of monomer and (potential) initiator solutions with initial concentrations as tabulated, were combined.

$†$ By i.r.-spectroscopy

${ }_{4}^{+}$Complex precipitates below 80 .

$p=0.1 \mathrm{~mm}$ ). Unlike the TIBA-glycolide complexes, the $\mathrm{AlBr}_{3}-\mathrm{glycolide}$ complexes were not soluble in toluene at room temperature. I.R.-spectra of the complexes in toluene could be recorded at about 90 .

Complex formation in the melt. Complex formation in the melt was investigated as follows. After the monomer was sublimed onto the upper part of the polymerization tube, an equimolar amount of pure initiator was added. The experiments were carried out in a dry box. Hereafter the tube was sealed under vacuum and kept at elevated temperatures for several hours. In these cases i.r.-spectra were recorded using $\mathrm{KBr}$ discs. The results with Nujol suspensions prepared in a dry box did not differ from those involving $\mathrm{KBr}$ discs.

Solution polymerization. The solution polymerization was based on procedures developed by Dittrich and Schulz [22] and by Kleine and Kleine [39]. Typically $1 \mathrm{~g}$ of sublimed monomer was dissolved in $10 \mathrm{ml}$ of dry toluene. After addition of $0.01 \mathrm{~g}$ initiator, the reaction mixture was refluxed for $24 \mathrm{hr}$ under $\mathrm{N}$, and the solution was characterized using i.r.-spectroscopy; the spectra were compared with those of a polymer solution which was previously made Reaction products (polymer) were isolated by solvent evaporation to dryness and subsequent washing with solvent.

\section{RESULTS AND DISCUSSION}

Table I summarizes the results on the complex formation of monomers and initiators or potential initiators at various temperatures. Detectable amounts of complexes were only observed with the use of $\mathrm{AlBr}_{3}$ or TIBA. In the experiments carried out with $\mathrm{L}(-)$-lactide and $\mathrm{D}, \mathrm{L}$-lactide, the absorption band at $935 \mathrm{~cm}$ ' which is characteristic of the ringvibration [40] did not disappear. This indicates that ring-opening polymerization did not occur. Using tetraphenyltin, observation of complex formation was more difficult because of the slight solubility of this initiator in benzene and in any other solvent $[41,42]$. Attempts to prepare complexes in the melt between $\mathrm{D}, \mathrm{L}$-lactide and tetraphenyltin were also not successful. Contrary to the complex formation found with the aluminium compounds, tin-(II)- and tin(IV)-complexes were not observed, in agreement with the fact that aluminium compounds form complexes more easily than tin compounds [43].

\section{$D, L$-Lactide-AlBr, complexes}

When equimolar solutions of $\mathrm{D}, \mathrm{L}$-lactide and sublimed $\mathrm{AlBr}_{3}$ in toluene were combined, a soluble complex characterized by the shifts of the carbonyl and ether frequencies shown in Table 2, was observed. The positions of the original $\mathrm{C}=\mathrm{O}$ and $\mathrm{C}-\mathrm{O}$ absorptions are in accord with those observed for solid L( - )-lactide by Schulz and Schwaab [40]. A shift in $v(\mathrm{C}=\mathrm{O})$ of $100 \mathrm{~cm}^{-1}$ towards longer wavelengths is indicative of a weakening of the $\mathrm{C}=\mathrm{O}$ bond. On the other hand, a shift in $v(\mathrm{C}-\mathrm{O})$ of $50 \mathrm{~cm}^{-1}$ towards shorter wavelengths points to an increased strength of the ether bond. The withdrawal of electrons from ester groups by $\mathrm{AlBr}_{3}$ can be envisaged as given in Scheme 2. The partial positive charge on the ether oxygen can be compensated to some extent by the inductive effect of the methyl group present.

Complex formation between D,L-lactide and sublimed $\mathrm{AlBr}_{3}$ in toluene was studied in more detail by adding successively very small amounts of a highly concentrated $\mathrm{AlBr}$, solution to a $0.1 \mathrm{M}$ D.L-lactide

Table 2. Characteristic i.r.-frequencies of $\mathrm{D}, \mathrm{L}$-lactide, glycolide and complexes with $\mathrm{AlBr}_{3}$ and $\mathrm{TIBA}$, dissolved in toluene*

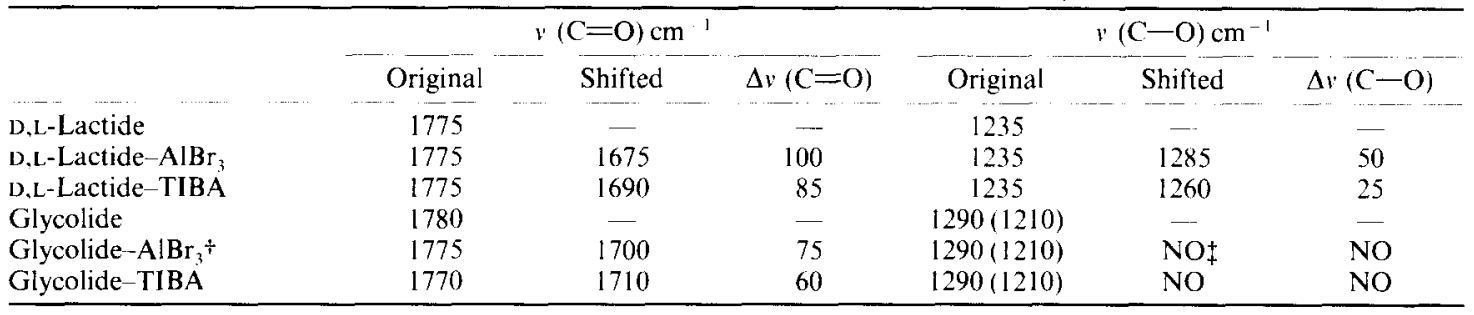

*Experimental conditions: see Table 1 .

†I.R.-spectrum recorded from toluene solution at about 90 .

$\ddagger$ NO: not observed. 


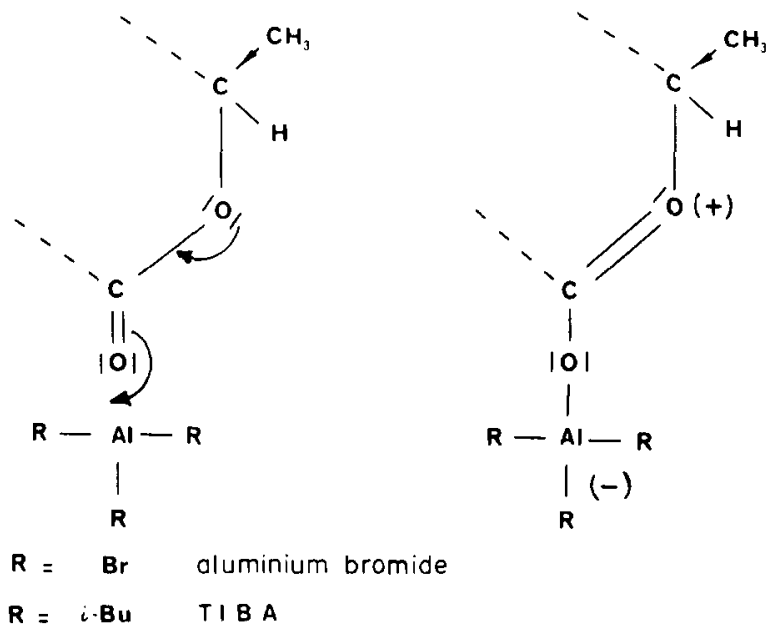

Scheme 2. Schematic representation of the withdrawal of electrons from an ester bond of $\mathrm{D}, \mathrm{L}-$ lactide by $\mathrm{AlR}_{3}(\mathrm{R}=\mathrm{Br}$ or $\mathrm{i}-\mathrm{Bu})$.

solution. The results are presented qualitatively in Table 3. Addition of the first small portion of $\mathrm{AlBr}_{3}$ resulted in a shift in $v(\mathrm{C}=\mathrm{O})$ of $100 \mathrm{~cm}^{-1}$ towards longer wavelengths and a shift in $v(\mathrm{C}-\mathrm{O})$ of $50 \mathrm{~cm}^{-1}$ towards shorter wavelengths. The areas of the shifted absorption bands were as yet very small in comparison with the areas of the original bands. The successive addition of more $\mathrm{AlBr}_{3}$ resulted in almost identical positions of the original and shifted bands, whereas decrease of the areas of the original bands and increase of that of the shifted bands occurred in a more or less parallel way. The observation that at a molar ratio 1:1 both the original and the shifted bands were present, can be explained by the fact that only half of all ester groups may have formed coordination bonds.

The necessity of using sublimed $\mathrm{AlBr}_{3}$ in these experiments and of working under strictly anhydrous conditions was shown by the observation that a precipitate was formed when solutions of $\mathrm{D}, \mathrm{L}$-lactide and non-sublimed $\mathrm{AlBr}_{3}$ in toluene were combined. The precipitate was isolated by evaporation to dryness after it was found that the supernatant solution did not show any characteristic absorption band. In the i.r.-spectrum of the precipitate, an absorption band corresponding to the original $v(\mathrm{C}-\mathrm{O})$ of solid $D, L$-lactide at $1760 \mathrm{~cm}^{-1}$ was found together with a new absorption band at $1630 \mathrm{~cm}^{-1}$, whereas no other new absorptions were observed. An absorption at $1630 \mathrm{~cm}^{-1}$ was also found in the i.r.-spectrum of non-sublimed $\mathrm{AlBr}_{3}$ and this absorption was not present if sublimed $\mathrm{AlBr}_{3}$ was used. If the latter compound was exposed to the air for only a short time, absorption at $1630 \mathrm{~cm}^{-1}$ appeared. The results of the elemental analysis of the precipitate showed a considerable lower content of $\mathrm{Br}$ than could be expected on the basis of the amount of $\mathrm{Al}$. In conclusion, although $\mathrm{D}, \mathrm{L}$-lactide was present in the precipitate, the new absorption at $1630 \mathrm{~cm}^{-1}$ must be attributed to partial hydrolysis of $\mathrm{AlBr}_{3}$ [44] instead of to complex formation between $\mathrm{D}, \mathrm{L}$-lactide and $\mathrm{AlBr}_{3}$.

\section{D,L-Lactide-TIBA complexes}

When equimolar solutions of $D, L$-lactide and TIBA were combined, a soluble complex was formed. The i.r.-spectrum of this complex showed similar but slightly smaller shifts as observed for the $1: 1$ D, L-lactide- $\mathrm{AlBr}_{3}$ complex (Table 2). In principle the insertion of $\mathrm{D}$,L-lactide into the $\mathrm{Al}-\mathrm{C}$ bond can be expected. Under the experimental conditions used, this insertion reaction did not play a major role because the characteristic ring vibration at $935 \mathrm{~cm}^{-1}$ was still present. The withdrawal of electrons from an

Table 3. I.R.-spectroscopic investigation of the formation of soluble $\mathrm{D}, \mathrm{L}$-lactide- $\mathrm{AlBr}_{3}$ complexes* in toluene by the successive addition of small portions of $\mathrm{AlBr}_{3}$ to $\mathrm{D}, \mathrm{L}$-lactide

\begin{tabular}{|c|c|c|c|c|}
\hline \multicolumn{2}{|c|}{ Absorption $(\mathrm{C}=\mathrm{O})$} & \multicolumn{2}{|c|}{ Absorption $(\mathrm{C}-\mathrm{O})$} & \multirow[b]{2}{*}{$\begin{array}{c}\mathrm{D}, \mathrm{L}-\mathrm{Lactide}-\mathrm{AlBr}_{3} \\
\text { (molar ratio) }\end{array}$} \\
\hline $\begin{array}{c}\text { Original } \\
\left(1775 \mathrm{~cm}^{-1}\right)\end{array}$ & $\begin{array}{c}\text { Shifted } \\
\left(1675 \mathrm{~cm}^{-1}\right)\end{array}$ & $\begin{array}{c}\text { Original } \\
\left(1235 \mathrm{~cm}^{-1}\right)\end{array}$ & $\begin{array}{c}\text { Shifted } \\
\left(1285 \mathrm{~cm}^{-1}\right)\end{array}$ & \\
\hline vs & - & vs & - & $100: 0$ \\
\hline vs & vw & vs & vw & $84: 16$ \\
\hline $\mathrm{s}$ & w & $\mathrm{s}$ & w & $73: 27$ \\
\hline $\mathrm{m}$ & $\mathrm{m}$ & $\mathrm{m}$ & $\mathrm{m}$ & $64: 34$ \\
\hline $\mathrm{m}$ & $\mathrm{m}$ & w & $\mathrm{m}$ & $57: 43$ \\
\hline w & $\mathrm{s}$ & vw & vs & $43: 57$ \\
\hline
\end{tabular}

vs-very strong; s-strong; m-medium; w-weak; vw-very weak.

${ }^{*} \mathrm{C}_{\text {complex }}$ is approx. $0.1 \mathrm{~mol}^{-1}$. 
ester group by TIBA may be presented schematically in the same way as in the case of $\mathrm{AlBr}_{3}$ (Scheme 2). The slightly smaller shifts observed for the complex with TIBA indicate that the $\mathrm{Al}$-atom in $\mathrm{AlBr}_{3}$ is slightly more electron deficient than in TIBA.

Complex formation between D,L-lactide and TIBA was studied in more detail in a similar way as described for $\mathrm{D}, \mathrm{L}$-lactide and $\mathrm{AlBr}_{3}$. Apart from the absolute values of the shifts, the results were comparable with those for the $\mathrm{AlBr}_{3}-\mathrm{D}, \mathrm{L}$-lactide complex formation (Table 3 ). The addition of the first portion of TIBA resulted in a shift in $v(\mathrm{C}=\mathrm{O})$ of $85 \mathrm{~cm}^{-1}$ towards longer wavelengths and a shift in $v(\mathrm{C}-\mathrm{O})$ of $25 \mathrm{~cm}^{-1}$ towards shorter wavelengths. The positions of the original and shifted absorption bands did not change when more TIBA was added, up to a molar ration of $1: 1$. Due to the relatively small shift in $v(\mathrm{C}-\mathrm{O})$ of $25 \mathrm{~cm}^{-1}$, the shifted band partially overlapped the original band. When the molar ratio TIBA-D,L-lactide was 2, all ester groups present could theoretically form coordination bonds with TIBA. The fact that weak absorption bands of the original carbonyl and ether groups were still present indicated that the equilibrium of the complex formation reaction was not totally to the side of the complex.

\section{Glycolide-AlBr, complexes}

Unlike the complexes of $\mathrm{D}, \mathrm{L}$-lactide and sublimed $\mathrm{AlBr}_{3}$, soluble complexes of glycolide and sublimed $\mathrm{AlBr}_{3}$ could not be prepared at room temperature. When an equal amount of a warm solution of sublimed $\mathrm{AlBr}_{3}$ in toluene $(c=0.1 \mathrm{~mol} / \mathrm{l})$ was added to a warm solution of glycolide in toluene $(c=0.1 \mathrm{~mol} / 1)$, a complex precipitated upon cooling and dissolved again at $80^{\circ}$. Therefore the i.r.-spectrum of the complex was recorded for a toluene solution at about 90\%. The characteristic frequency shifts are summarized in Table 2 .

The carbonyl group of glycolide absorbs at practically the same wavelength as the carbonyl group of $D, L-l a c t i d e$, in agreement with observations of Goulden and Millard [45]. After complex formation with $\mathrm{AlBr}_{3}$ a shift in $v(\mathrm{C}=\mathrm{O})$ of $75 \mathrm{~cm}^{-1}$ towards longer wavelengths was observed which is slightly less than the shift in $v(\mathrm{C}=\mathrm{O})$ observed for the $\mathrm{D}, \mathrm{L}$-lactide $-\mathrm{AlBr}_{3}$ complex.

Whereas the original ether absorption for pure $\mathrm{D}, \mathrm{L}$-lactide dissolved in toluene was found at $1235 \mathrm{~cm}^{-1}$, the i.r.-spectrum of pure glycolide in toluene showed an intense absorption at $1290 \mathrm{~cm}^{-1}$ and a very weak absorption at $1210 \mathrm{~cm}^{-1}$. Kogan et al. [15] assigned a band at $1215 \mathrm{~cm}^{-1}$ to the stretching vibration of the ether group of glycolide; the occurrence of a band at $1290 \mathrm{~cm}^{-1}$ was not mentioned. An extensive survey of the literature with respect to the ether absorption of glycolide only revealed some Raman-spectroscopic data [46]. The Ramanspectrum of a glycolide melt showed a medium strong band at $1224 \mathrm{~cm}^{-1}$ and a weak band at $1290 \mathrm{~cm}^{-1}$. According to Colthup et al. [47], the ether $\mathrm{C}-\mathrm{O}$ stretching frequency of esters, which actually involves some interaction with all $\mathrm{C}-\mathrm{C}$ bonds in the molecule, is near $1200 \mathrm{~cm}^{-1}$. Only acetates absorb at $1260-1230 \mathrm{~cm}$. The ether absorption for the unstrained six-membered D,L-lactide found at
$1235 \mathrm{~cm}^{-1}$ fits very well with these data. For glycolide both the absorption at $1210 \mathrm{~cm}^{-1}$ (vw) and the absorption at $1290 \mathrm{~cm}^{-1}$ (s) can be attributed to the ether group. An explanation for the occurrence of the two bands with different intensities might be a mixing of $\mathrm{C}-\mathrm{C}$ and $\mathrm{C}-\mathrm{O}$ stretching vibrations [48].

The i.r.-spectrum of a solution of the glycolide $-\mathrm{AlBr}_{3}$ complex in toluene at higher temperatures did not show a shift of the original absorption at $1290 \mathrm{~cm}^{-1}$. This result is in agreement with the fact that the absorption at $1290 \mathrm{~cm}^{-1}$ originates from a coupling of $\mathrm{C}-\mathrm{O}$ and $\mathrm{C}-\mathrm{C}$ frequencies and thus responds in a different way to complex formation. The absorption at $1210 \mathrm{~cm}^{-1}$ was so weak that significant changes could not be observed.

Kogan et al. [15] also investigated the formation of complexes between glycolide and several Lewis acids. After mixing equimolar benzene solutions of glycolide and $\mathrm{AlBr}_{3}$, a precipitate was obtained with a molar ratio glycolide- $\mathrm{AlBr}_{3}$ of 1:4. Although Kogan and co-workers had expected a shift of $100 \mathrm{~cm}^{-1}$ towards longer wavelengths for the carbonyl group, only a disappearance of the band at $1215 \mathrm{~cm}^{-1}$ corresponding to the ether frequency was observed. Consequently it was concluded that the ether-oxygen was the more active electron donor centre in the glycolide molecule, a conclusion not in agreement with our results obtained from i.r.-studies with solutions.

\section{Glycolide-TIBA complexes}

Unlike the complexes between $\mathrm{AlBr}_{3}$ and glycolide, complexes between TIBA and glycolide were soluble at room temperature. When equimolar solutions of glycolide and TIBA in toluene were combined, a soluble complex was formed and was characterized by a similar but slightly smaller shift in $\vee(C=0)$, $60 \mathrm{~cm}^{-1}$, than the shift observed for the $1: 1$ glycolide- $\mathrm{AlBr}_{3}$ complex at higher temperatures (Table 2), TIBA being a slightly weaker Lewis acid than $\mathrm{AlBr}_{3}$. The shift in $v(\mathrm{C}=\mathrm{O})$ of $60 \mathrm{~cm}^{-1}$ is also slightly smaller than the shift in $v(\mathrm{C}=\mathrm{O})$ of $85 \mathrm{~cm}^{-1}$ observed for the soluble complexes of TIBA and D,L-lactide. A similar phenomenon was observed for the $\mathrm{AlBr}_{3}$ glycolide complexes in comparison with their D,L-lactide counterparts. Apparently the glycolide molecule is less capable to donate electrons than the D,L-lactide molecule. It is obvious that, in the case with glycolide complexes, the induced positive charge on the ether-oxygen cannot be compensated by the electron donating effect of a methyl group as is the case with D,L-lactide (Scheme 2). As a result the $\mathrm{C}=\mathrm{O}$ bond in the glycolide complexes retains more double bond character which is reflected by the smaller shifts in $v(\mathrm{C}=\mathrm{O})$.

The i.r.-spectra of the glycolide-TIBA complexes did not show a shift of the absorption at $1290 \mathrm{~cm}^{-1}$. Again significant changes of the very weak absorptions at $1210 \mathrm{~cm}{ }^{\prime}$ could not be observed.

The formation of complexes between glycolide and TIBA was studied in more detail at molar ratios of TIBA-glycolide $>1$. If the molar ratio TIBAglycolide was 2, a weak band corresponding to the original $\mathrm{C}=\mathrm{O}$ absorption was still present, indicating that complex formation was not complete. 


\section{Solution polymerization studies}

Solution polymerization studies were performed with $\mathrm{SnCl}_{4}, \mathrm{AlBr}_{3}$ and TIBA as initiators. $\mathrm{SnCl}_{4}$ has been used successfully as an initiator for the solution polymerization of lactide $[22,39]$. Our investigation showed that with $\mathrm{SnCl}_{4}$ moderately high molecular weight poly(D,L-lactic acid) $\left(\bar{M}_{n^{\prime}}=2-2.5 \times 10^{4}, \bar{M}_{n}=\right.$ $1-1.5 \times 10^{4}$ ) could be obtained.

$\mathrm{AlBr}_{3}$ has not been reported as an initiator for the ring-opening polymerization of lactones. The attempted solution polymerization of $\mathrm{D}, \mathrm{L}$-lactide or glycolide in toluene initiated with sublimed $\mathrm{AlBr}_{3}$ failed to produce any polymer. When the polymerization of glycolide was attempted with $\mathrm{AlBr}_{3}$ and traces of water, poly(glycolic acid) was formed as indicated by i.r.-spectroscopy.

The solution polymerization with TIBA afforded moderately high molecular weight poly(D,L-lactic acid) $\left(\bar{M}_{w}=1.5-2 \times 10^{4}, \bar{M}_{n}=1-1.5 \times 10^{4}\right)$. We also investigated the possibility of preparing poly(D,Llactic acid) starting from a complex of D,L-lactide and TIBA (molar ratio: 1) dissolved in toluene. The amount of $\mathrm{D}, \mathrm{L}$-lactide was increased in a stepwise manner up to a molar ratio $30: 1$. In between the addition of each new portion of D,L-lactide, the reaction mixture was refluxed for several hours and an i.r.-spectrum was recorded. Upon successive addition of $\mathrm{D}, \mathrm{L}-$ lactide, the shifted bands corresponding to $v(\mathrm{C}-\mathrm{O})$ disappeared gradually, whereas the i.r.spectra became gradually more like the i.r.-spectrum of poly(D,L-lactic acid) dissolved in toluene. I.R.spectroscopic analysis of the reaction product formed after the attempted solution polymerization of glycolide initiated with TIBA indicated the formation of poly(glycolic acid).

\section{Complex formation related to polymerization}

The strong Lewis acid $\mathrm{AlBr}_{3}$ formed complexes with D,L-lactide and glycolide. Polymerization of glycolide using $\mathrm{AlBr}_{3}$ could only be achieved after the addition of traces of water. A similar observation was made by Cherdron et al. [10] when Lewis acids such as $\mathrm{AlCl}_{3}$ were used as initiator for the polymerization of other lactones. These results strongly suggest that in our case $\mathrm{HBr}$, formed by hydrolysis of $\mathrm{AlBr}_{3}$, was the actual initiating species. In the case of $\mathrm{SnCl}_{4}$, no detectable amounts of complexes were observed which seems at first somewhat contradictory to the observation by Amass and Hay [49] that $\mathrm{SnCl}_{4}$ formed a solid 1:2 molar complex with $\epsilon$-caprolactam, characterized by a shift of the carbonyl band and the presence of a free $\mathrm{N}-\mathrm{H}$ band. However, in comparison with the carbonyl oxygen of an ester group, the carbonyl oxygen of an amide group has an increased electron density due to the great tendency of the nitrogen atom to donate electrons $[50,51]$. These authors also stated that the polymerization of $\epsilon$-caprolactam using $\mathrm{SnCl}_{4}$ at elevated temperatures is actually initiated with $\mathrm{HCl}$. $\mathrm{SnCl}_{4}$ also proved to be a rather effective initiator for the solution polymerization of D,L-lactide. Lilly and Schulz [5] suggested that the initiation of $\mathrm{L}(-)$-lactide involved the formation of a coordination bond between $\mathrm{SnCl}_{4}$ and an ether oxygen followed by acyl-oxygen bond cleavage and the release of $\mathrm{Cl}^{-}$. In view of our results with $\mathrm{AlBr}_{3}$ as mentioned above, it might also be possible that, in the case of $\mathrm{SnCl}_{4}, \mathrm{HCl}$ was the actual initiating species. A possible mechanism for the initiation and polymerization of lactide and glycolide (in toluene) with strong acids such as $\mathrm{HBr}$ or $\mathrm{HCl}$ is depicted in Scheme 3. First protonation will take<smiles>[R]C1OC(=O)C([R])([R])OC1=O</smiles>

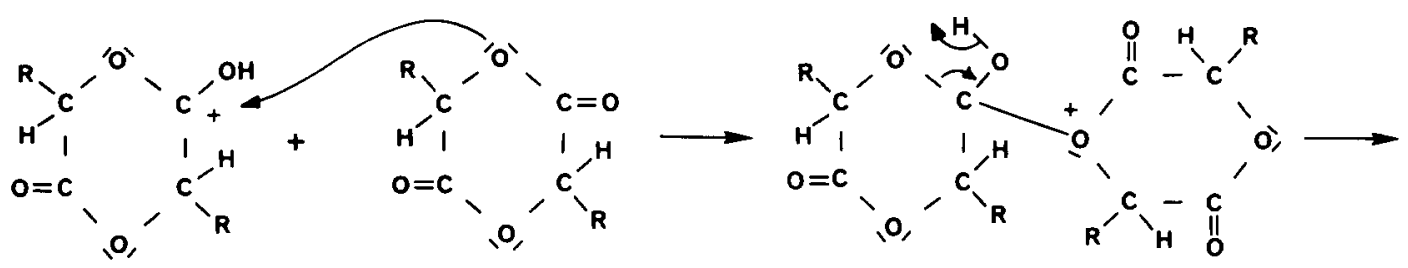

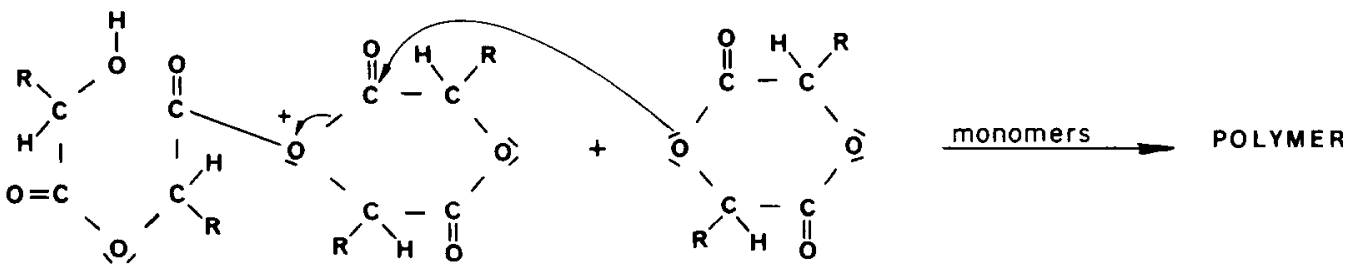

Scheme 3. Possible reaction pathway for the ring-opening polymerization of glycolide $(R=H)$ or lactide $\left(\mathrm{R}=\mathrm{CH}_{3}\right)$ initiated with strong protonic acids. 

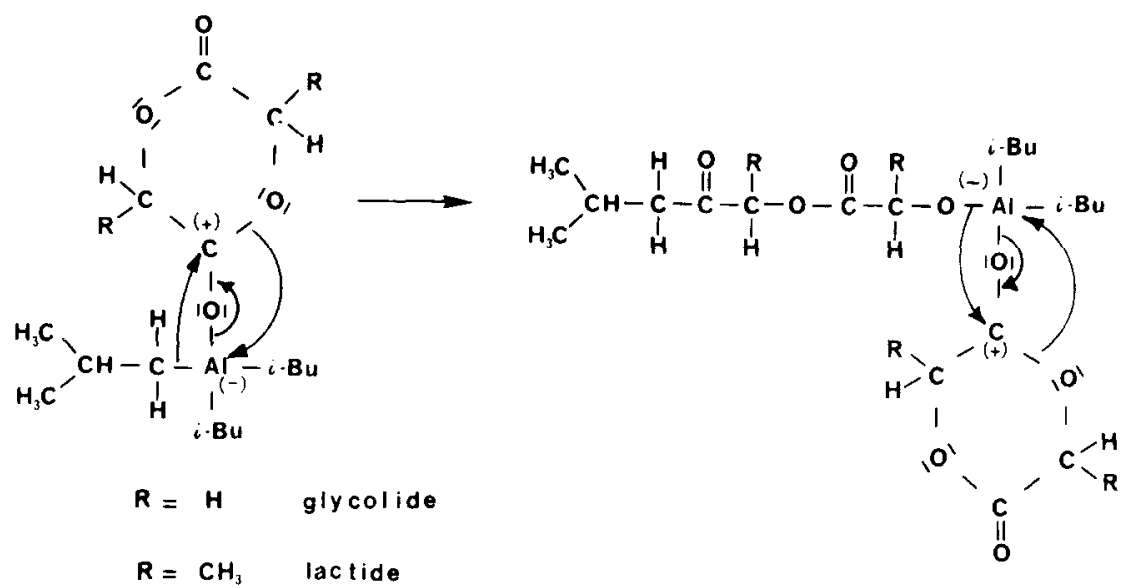

Scheme 4. Coordination insertion mechanism for glycolide $(\mathrm{R}=\mathrm{H})$ and lactide $\left(\mathrm{R}=\mathrm{CH}_{3}\right)$ initiated with

TIBA.

place on one of the two available carbonyl oxygens followed by a proton shift and an $\mathrm{S}_{\mathrm{N}} 2$-type transesterification reaction. According to Mhala and Mishra [52] the acid catalyzed hydrolysis of $\mathrm{D}, \mathrm{L}$-lactide involves as the first step protonation of an ether oxygen; this view seems not to be in agreement with the present weight of physical evidence which shows that esters are initially protonated on the carbonyl and not on the ether oxygen [53].

Using the mechanism depicted in Scheme 3, polymerization with $\mathrm{AlBr}_{3}$ should lead to charge separation which might explain that $\mathrm{AlBr}_{3}$ as such is not a good initiator.

The only compound that could both form complexes with D,L-lactide or glycolide and initiate their polymerization under anhydrous solution conditions was TIBA. According to the often cited [28, 31] mechanism proposed by Cherdron et al. [10], the cationic initiation of a lactone takes place via attack of a cationic species on the ether oxygen followed by acyl-oxygen bond cleavage. The propagation step involves the attack of an acylium ion upon the ether oxygen of the next monomer. Contrary to this, some authors $[11,13,14]$ proposed as the propagation step the attack of an acylium ion upon the carbonyl oxygen of the next lactone monomer; a satisfactory mechanism for the subsequent ring-opening however was not given. Our results show that only the carbonyl group of $\mathrm{D}, \mathrm{L}$-lactide or glycolide was involved in the complex formation with TIBA (Scheme 2) suggesting that the classical cationic initiation and propagation mechanism proposed by Cherdron et al. [10] is not applicable to our system. An acceptable mechanism for the polymerization of D,L-lactide and glycolide with TIBA is the coordination insertion mechanism proposed by Dittrich and Schulz [22] for the polymerization of $\mathrm{L}(-)$-lactide initiated with diethylzinc, involving acyl-oxygen bond breakage (Scheme 4). After the coordination of TIBA with D, L-lactide or glycolide, insertion of the lactone monomer takes place into an aluminium-carbon bond. The propagation step involves the insertion of monomer into an aluminium-oxygen bond. Other authors [23, 24, 28] proposed a coordination insertion mechanism for lactones involving a coordination of the monomer to the metal atom of the organometallic compound through the ether oxygen. Our results on the complex formation with TIBA are in disagreement with such a mechanism. Brode and Koleske [31] did not succeed in the synthesis of a low molecular 1:1 molar insertion product of stannous octoate or trimethyltin acetate with caprolactone under a variety of experimental conditions. The fact that, also in this study, no complex formation was observed with stannous octoate nor with tetraphenyltin (both very effective initiators in melt polymerizations of lactide or glycolide) warrants further research to elucidate the mechanism involved.

\section{CONCLUSIONS}

1. $\mathrm{AlBr}_{3}$ and TIBA form complexes with $\mathrm{D}, \mathrm{L}$-lactide or glycolide in toluene via the carbonyl oxygen. Using similar conditions, no complexes were observed with $\mathrm{L}(-)$-lactide and tetraphenyltin or stannous octoate, and with $\mathrm{L}(-)$-lactide or D, L-lactide and $\mathrm{SnCl}_{4}$.

2. The first step of the polymerization of D,L-lactide or glycolide with TIBA in apolar solvents can be envisaged as an insertion of the D,L-lactide or glycolide monomer in an aluminium-carbon bond after the initial formation of a TIBA-D,L-lactide or glycolide complex. In the following step, monomer insertion into an aluminium-oxygen bond is expected.

3. When $\mathrm{AlBr}_{3}$ or $\mathrm{SnCl}_{4}$ are used as the initiators for the ring-opening polymerization of D, L-lactide or glycolide in an apolar solvent such as toluene, their hydrolysis products $(\mathrm{HBr}$ and $\mathrm{HCl}$ respectively) might be the true initiating species.

4. The mechanism of the initiation of D,L-lactide or glycolide with strong protonic acids may be explained as an $S_{N}$ 2-type transesterification reaction involving as the first step protonation of a carbonyl oxygen.

Acknowledgements-The authors thank Mr R. G. Eggink and $\mathrm{Mr} \mathrm{P}$. A. Schut for their contributions to the synthetic part of this investigation and Dr R. Visser and Prof. Dr ir D. N. Reinhoudt for their valuable discussions. 


\section{REFERENCES}

1. R. L. Kronenthal, Polymers in Medicine and Surgery, (Edited by R. L. Kronenthal, Z. Over and E. Martin), p. 119. Plenum Press, New York (1975).

2. E. J. Frazza and E. E. Schmitt, J. biomed. Mater. Res. Symp. 1, 43 (1971).

3. P. H. Craig, J. A. Williams, K. W. Davis, A. D. Magoun, A. J. Levy, S. Bogdanski and J. P. Jones, Surgery Gynec. Obstet. 141, 1 (1975).

4. L. Feenstra, B. W. C. van der Ven, F. E. Kohn and J. Feijen, Int. J. artif. Organs 3, 354 (1980).

5. E. Lilly and R. C. Schulz, Makromolek. Chem. 176, $1901(1975)$

6. J. A. P. P. van Dijk, J. A. M. Smit, F. E. Kohn and J. Feijen, J. Polym. Sci., Polym. Chem. Ed. (in press).

7. R. C. Schulz, Proc. IUPAC Int. Symp. Makromolek. Chem., p. 185, Budapest (1969).

8. G. J. van Hummel, S. Harkema, F. E. Kohn and J. Feijen, Acta cryst. B38, 1679 (1982).

9. J. L. Brash and D. J. Lyman, Cyclic Monomers, High Polymers, Vol. XXVI, (Edited by K. C. Frisch), p. 147. Wiley-Interscience, New York (1972).

10. H. Cherdron, H. Ohse and F. Korte, Makromolek. Chem. 56, 179 (1962).

11. Y. Yamashita, T. Tsuda, O. Masahiko and Sh. Iwatsuki, J. Polym. Sci. A-1 4, 2121 (1966).

12. Y. Yamashita, K. Ito, K. Chiba and S. Kozawa, Polym. J. 3, 389 (1972).

13. G. S. Sanina and E. B. Lyudvig, Dokl. Akad. Nauk SSSR 229, 1400 (1976).

14. G. S. Sanina and E. B. Lyudvig, Dokl. Akad. Nauk SSSR 230, 153 (1976).

15. V. A. Kogan, N. N. Kharabaev, A. S. Burlov, V. P. Sokolov, O. A. Osipov, V. A. Savin and V. G. Maslov, Zh. obshch. Khim. 48, 655 (1978).

16. H. Cherdron, H. Ohse and F. Korte, Makromolek. Chem. 56, 187 (1962).

17. Y. Yamashita, T. Tsuda, H. Ishida, A. Uchikawa and Y. Kuriyama, Makromolek. Chem. 113, 139 (1968).

18. Y. Yamashita, Polym. Prepr. 21, 51 (1980).

19. S. Somkowski and S. Panczek, Macromolecules 13, 229 (1980).

20. P. Sigwalt, Angew. Makromolek. Chem. 94, 161 (1980).

21. J. G. Noltes, F. Verbeek and H. G. J. Overmars, $J$. organometal. Chem. 24, 257 (1970).

22. W. Dittrich and R. C. Schulz, Angew. Makromolek. Chem. 15, 109 (1971).

23. T. Ouhadi, Ch. Stevens and $\mathrm{Ph}$. Teyssié, Makromolek. Chem. Suppl. 1, 191 (1975).

24. A. Hamiton, T. Ouhadi, R. Jerome and Ph. Teyssié, $J$. Polym. Sci., Polym. Chem. Ed. 15, 865 (1977).

25. J. V. Koleske and R. D. Lundberg, J. Polym. Sci. A-2 7, 897 (1969)

26. R. A. Fouty, Can. Patent 808, 731 (1969)

27. R. G. Sinclair, U.S. patent 4,045, 418 (1975).

28. R. H. Young, M. Matzner and L. A. Pilato, Acta chem. scand. Symp. Ser. 59, 152 (1977).
29. R. D. Lundberg and E. F. Cox, Ring-Opening Polymerization, Vol. 2, (Edited by K. C. Frisch and S. L. Reegen), p. 247. Marcel Dekker, New York (1969).

30. R. D. Lundberg, J. V. Koleske and K. B. Wischmann, J. Polym. Sci. A-1, 7, 2915 (1969).

31. G. L. Brode and J. V. Koleske, J. Makromolek. Sci-Chem. A6, 1109 (1972).

32. J. G. van Ommen, H. J. van der Ploeg, P. C. J. M. van Berkeland and P. Mars, J. mol. Catal. 2, 409 (1977).

33. R. K. Kulkarni, K. C. Pani, C. Neuman and F. Leonard, U.S. Nat. Tech. Inform. Serv. AD Rept. No. 636, $716(1969)$.

34. R. G. Sinclair and G. H. Gynn, U.S. Nat. Tech. Inform Serv. AD Rept. No. 748, 411 (1972).

35. Ch. E. Lowe, U.S. Patent 2, 668, 192 (1954).

36. W. R. Sorenson and T. W. Campbell, Preparative Methods of Polymer Chemistry, 2nd edn, p. 363. Interscience, New York (1968).

37. W. R. Sorenson and T. W. Campbell, Preparative Methods of Polymer Chemistry, 2nd edn, p. 12. Interscience, New York (1968).

38. H. J. de Liefde Meyer, M. J. Jansen and G. J. H. van der Kerk, Studies in Organic Chemistry of Vanadium, p. 40. Institute for Organic Chemistry, TNO, Utrecht, The Netherlands (1963).

39. J. Kleine and H. H. Kleine, Makromolek. Chem. 30, 23 (1959).

40. R. C. Schulz and J. Schwaab, Makromolek. Chem. 87, 90 (1965).

41. W. Strohmeier and K. H. Miltenberger, Chem. Ber. 91 , 1357 (1958).

42. M. Vitoria and J. Walkley, Trans. Faraday Soc. 65, 57 (1969).

43. G. E. Coates, M. L. H. Green, P. Powell and K. Wade, Principles of Organometallic Chemistry, p. 103 and 126. Methuen, London (1968).

44. D. P. N. Satchell and R. S. Satchell, Chem. Rev. 69, 251 (1969).

45. J. D. S. Goulden and B. J. Millard, Org. Mass Spectrom. 2, 893 (1969).

46. L. Kahovec and K. W. F. Kohlraush, Z. phys. Chem. 193, 188 (1944).

47. N. B. Colthup, L. H. Daly and S. E. Wiberley, Introduction to Infrared and Raman Spectroscopy, p. 248. Academic Press, New York (1964).

48. L. J. Bellamy, The Infrared Spectra of Complex Molecules, p. 196. Chapman \& Hall, London (1975).

49. A. J. Amass and J. N. Hay, Makromolek. Chem. 103 , 244 (1967).

50. H. C. Brown, J. H. Brewster and H. Shechter, J. Am. chem. Soc. 76, 467 (1954).

51. J. Dale, Stereochemistry and Conformational Analysis, p. 82. Universitetsforlaget, Oslo (1978).

52. M. M. Mhala and J. P. Mishra, Ind. J. Chem. 8, 243 (1970).

53. J. March, Advanced Organic Chemistry, 2nd edn, p. 349. McGraw-Hill, Tokyo (1977). 